\title{
Daratumumab/Lenalidomide/Dexamethasone Regimen
}

National Cancer Institute

\section{Source}

National Cancer Institute. Daratumumab/Lenalidomide/Dexamethasone Regimen. NCI

Thesaurus. Code C136268.

A chemoimmunotherapy regimen consisting of daratumumab, lenalidomide and dexamethasone that is used for the treatment of plasma cell myeloma. 